Vol. 6(4), pp. 342-350, April 2014

DOI: $10.5897 /$ J BC 2013.0646

Artic le Number: 666C 2C C 46769

ISSN 2141-243X

Copyright (c) 2014

International Journal of Biodiversity

Author(s) retain the copyright of this a ricle

and Conservation

http://www.academic joumals.org/IJ BC

\title{
Assessment of downstream impact of Bahir Dar tannery effluent on the head of Blue Nile River using macroinvertebrates as bioindicators
}

\author{
Assefa Wosnie $^{1_{*}}$ and Ayalew Wondie ${ }^{2}$ \\ 'Dilla University, P O Box 419, Dilla, Southern Nations, Nationalities, and Peoples' Region, Ethiopia. \\ ${ }^{2}$ Bahir Dar University, P.O Box 79, Bahir Dar, Ethiopia.
}

Received 25 October, 2013; Accepted 11 March, 2014

\begin{abstract}
A study was conducted to determine the downstream impact of Bahir Dar Tannery wastewater on the head of Blue Nile River using macroinvertebrates as bioindicators. Four sampling sites (one upstream and three downstream) were selected along the river and samples were collected from October to March, 2010/11. Macroinvertebrates were collected using standard dip net based on the Rapid Bioassessment Protocols for use in streams and wadeable rivers and identified to the family level. A total of 9,162 individuals belonging to 28 families were collected during the study period. Results of analysis of variance (ANOVA) showed that, there was significant difference in macroinvertebrate metrics among sampling sites. Percent Ephemeroptera Plecoptera Trichoptera (EPT) Index, Shannon Diversity Index and Benthic Macroinvertebrate Index were higher and percent Diptera, Chironomidae and Hilsenhoff Family level biotic index were lower at the reference site. The categorization of sites based on Benthic macroinvertebrate index value indicated that the site just below the effluent discharge and $200 \mathrm{~m}$ from it were severely to slightly, the last downstream site moderately to less and the reference or upstream site very little to none impacted. The water quality at these sites was also very poor to poor, fair to good and very good to excellent, respectively. The most impacted sites ranked last in all sensitive metrics while the reference ranked first in sensitive metrics indicating the severe impact of the effluent on downstream sites. The result gave the trends of pollution of the river by the effluent and the urgent need for measures to be taken.
\end{abstract}

Key words: Tannery effluent, macroinvertebrates, bioindicators, Blue Nile River.

\section{INTRODUCTION}

Rapid population growth, urbanization and industrial development have been adversely degrading the environment (Mason, 1990) by their effect through loss of biodiversity and pollution from wastes. Industrialization, like other human activities that impact on the environment, often results in pollution and degradation. It carries inevitable costs and problems in terms of pollution of the air, water resources and general degradation of the natural environment (Suflita et al., 1983). Industrial waste is the most common point source of water pollution in the present day (Ogedengbe and Akinbile, 2004) and it increases yearly due to the fact that industries are

${ }^{*}$ Corresponding author. E-mail: assefawosnie@gmail.com.

Author(s) agree that this article remain permanently open access under the terms of the Creative Commons Attribution License 4.0 International License 
increasing because most countries are getting industrialized. In Ethiopia too, industries are increasing in number turning out wastes which are peculiar in terms of type, volume and pollution strength depending on the type of industry, raw materials used and process and technological variations applied to the process.

As compared to other industries, leather tanning is one of the most polluting activities (Khan et al., 1999) as it consumes huge amount of water in several stages, generating an enormous sum of liquid effluents (Farenzena et al., 2005) which are hazardous for the environment to which they are discharged. Tannery wastewater is highly polluted in terms of biological oxygen demand (BOD), chemical oxygen demand (COD), suspended solids (SS), Nitrogen, conductivity, sulphate, sulphide and chromium (Mondal et al., 2005) and in most developing countries tannery effluents are discharged directly into sewers or water bodies without treatment (Verheijen et al., 1996; Favazzi, 2002). In Ethiopia also industries turnout wastes directly into the nearby water bodies. This makes industrial and chemical pollution to become the third major problem in the country and one of the great environmental concerns (Zinabu and Zerihun, 2002). This is becoming evident through the pollution of water bodies and human habitat in the major cities, rivers and lakes. So it is very important to assess the ecological impact of the wastes.

Usually, chemical and physical monitoring was widely utilized to assess the extent of pollution of water bodies from point and non-point sources. Recently, rivers sustaining rich and diverse fauna have been recognized for their resource value (Abel, 1996). A more comprehensive approach of biological assessment of water quality recently introduced the Benthic Macroinvertebrate Index (BMI) (Karr, 1981). This has led to an increased focus towards stream ecological well being, and the use of ecological indicators' of water quality (Yandora, 1998).

In Ethiopia and to larger extent the whole of Africa, the use of macro-invertebrate for assessment and monitoring of stream conditions is still not well practiced. However, rapid bio-assessment of water quality in rivers has been used in a National Biomonitoring Programme in South Africa (Dallas, 1997). In East Africa, only few studies have attempted to describe the structure and composition of macro-invertebrates in lotic systems. Mathooko (2002), Barnard and Biggs (1988) and Kinyua and Pacini (1991) in Kenya and Tumiwesigye et al. (2000) in Uganda studied the macro-invertebrate composition of the rivers and lakes. In Ethiopia, Baye (2006) and Solomon (2006) studied the relation between physicochemical change and biological communities in rivers with different sources of pollution. Hayal and Seyoum (2009) studied water quality and macroinvertebrates index of biotic integrity of wetlands. On the other hand, Birnesh (2007) studied downstream pollution profile of Tikur Wuha River from point source. So in Ethiopia, the use of macroinver- tebrates in assessing pollution status is in its infant stage. Hence, this study aims to assess the downstream impact of Bahir Dar Tannery effluent on the Blue Nile River using macroinvertebrate as bioindicators.

\section{MATERIALS AND METHODS}

\section{Description of the study area}

The study was conducted in Bahir Dar, the capital city of Amhara Region which is situated on the southern shore of Lake Tana, the source of Blue Nile (Abay) River. Bahir Dar Textile factory and Tannery are the most important industries in the city. Both the textile factory and the tannery discharged their effluent directly into the Blue Nile River. The downstream part of the river is used for domestic activities including drinking, irrigation and recreation (swimming and bathing). The use of the river in this way may lead to bioaccumulation of toxic pollutants like chromium which is hazardous for human beings as well as livestocks.

\section{Sampling}

The study was conducted from October, 2010 to March, 2011. This time was selected to sample from both dry and wet periods so as to avoid possible seasonal effect. Based on the method stated in Klemm et al. (1990) which is mostly used to specify sites for studying pollution from point sources, four sampling sites (one upstream and three downstream) were established on the study area. All the sites had almost similar microhabitats (pools and vegetated areas) and designated as $S_{1}$ to $S_{4}$ as shown in Figure 1. Qualitative macroinvertebrate data collection was carried out at the same sampling sites based on the Rapid Bioassessment Protocols that are used in streams and wadeable rivers (Barbour et al., 1999). Macroinvertebrates were sampled using standardized dip net (500 $\mu \mathrm{m}$ mesh size). To maintain the consistency of sampling effort, a sample was generally obtained within $30 \mathrm{~min}$ at each site and a sampling reach length of $100 \mathrm{~m}$ was used. Then macroinvertebrates collected from all microhabitats of each site were pooled so as to obtain a single sample from each site. In the field, macroinvertebrate samples were preserved in $70 \%$ ethanol or $10 \%$ formalin (for highly polluted sites) for later sorting and identification. All the organisms in the sample were enumerated and identified to the lowest practical taxonomic level (family level) using a dissecting microscope and standard keys (Edmondson, 1959; Jessup et al., 1999; Gooderham and Tysrlin, 2002; Bouchard, 2004).

\section{Data analysis}

Macroinvertebrate metrics were calculated from the sample data and final Benthic Macroinvertebrate Index (BMI) was calculated from aggregation of these metrics

\section{Metrics selection and index development}

Metrics to be included in the Benthic Macroinvertebrate Index (BMI) for this study were selected from a list of macroinvertebrate community attributes by testing their responsiveness to disturbance and redundancy with other metrics. Based on this, eight nonredundant metrics (Percent Taxa Richness, Percent Ephemeroptera Plecoptera Trichoptera (EPT) Index, Percent Diptera, Percent Chironomidae, Percent Dominant Taxa, Percent Non-Insect Taxa, Hilsenhoff Family-level Biotic Index (HFBI), and Shannon Diversity Index (SDI) that responded well to disturbance 


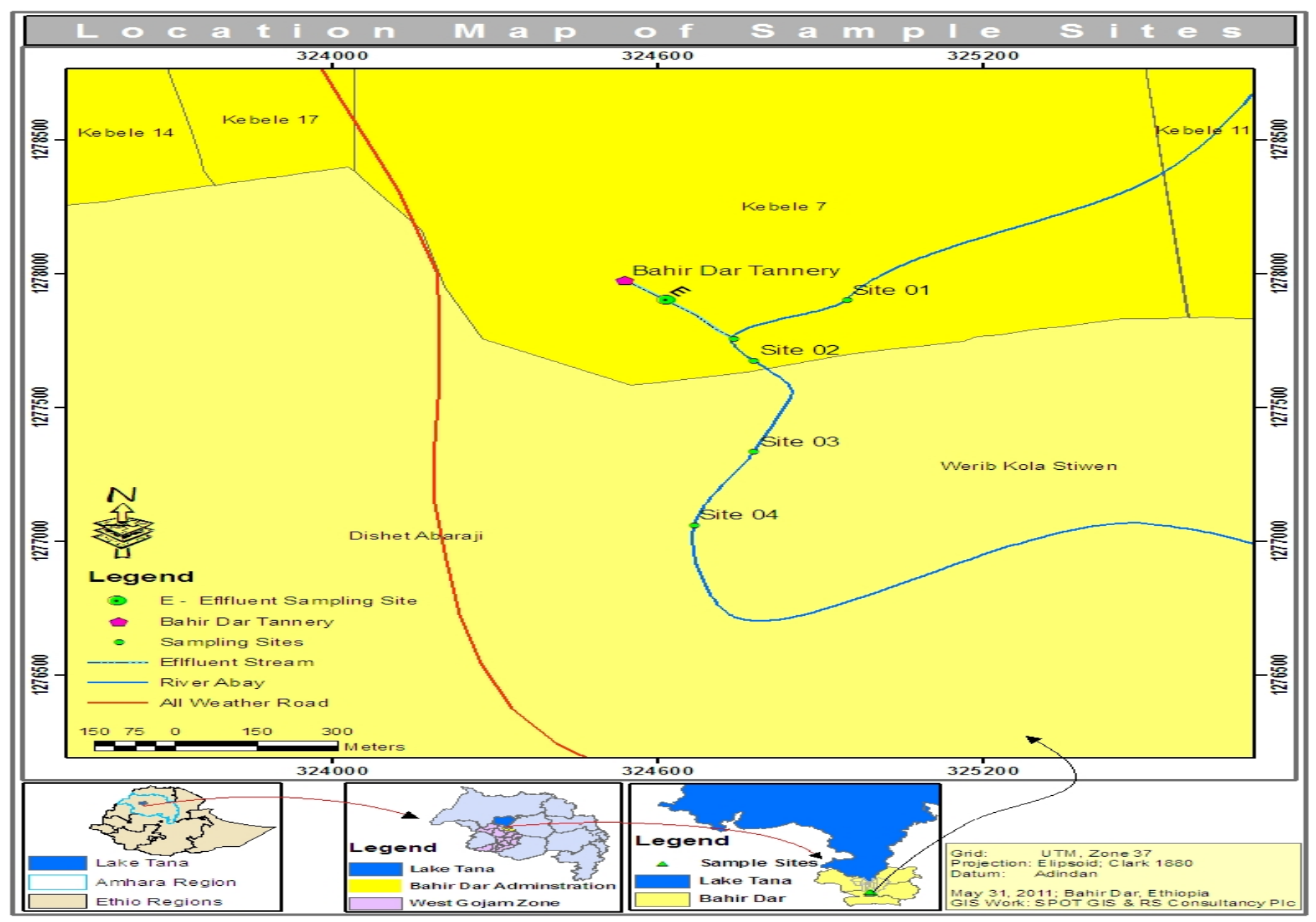

Figure 1. Map showing the study location and sampling sites along the Blue Nile River.

were selected. The metrics values were then converted to a standardized score using scoring criteria by examining relationships between individual metric scores and an indicator of impairment across a range of impairment levels, including undisturbed reference conditions. The standardized scores were then added to produce the final multimetric score of Benthic Macroinvertebrate Index (BMI) for each site. BMI values were calculated in this way for each site and then standardized to 100-point scale. Based on this $\mathrm{BMI}$, value the sites were categorized in to various impairment levels which in turn determine the water quality at each site (Table 3).

\section{Statistical data analysis}

Macroinvertebrate percentage data were Arcsine transformed before analysis. One-way ANOVA was used to compare the magnitude of macroinvertebrate metrics among the sampling sites. Means were separated using Tukey HSD.

\section{RESULTS AND DISCUSSION}

A total of 28 taxa comprising 9,162 individuals were collected from the four sites during the study period. As shown in Table 1, the total number of taxa present at each site ranged from $18\left(S_{2}\right)$ to $25\left(S_{1}\right)$, while the total number of individuals present at each site ranged from $988\left(\mathrm{~S}_{1}\right)$ to $5129\left(\mathrm{~S}_{2}\right)$. The major components of the community were Chironomidae (3520), Ephydridae (1584), Clucidae (860), Baetidae (458). The families least encountered were Heptagenidae (1), Caenidae (5) Hydropsychidae (6) and Gerridae (9). The EPT families, Aeshnidae and Naucoridae were absent from the most impacted sites $\left(S_{2} \& S_{3}\right)$ while Clucidae, Ephydridae, and Chironomidae were more abundant at these sites (Table 1). The result also showed that the number of individuals increased with increase in perturbation while the number of taxa showed a decreasing trend.

\section{Macroinvertebrate metrics characterization along Blue Nile River}

Benthic macroinvertebrate assemblage data which were 
Table 1. Number of macroinvertebrates collected from the study sites in 2010/11.

\begin{tabular}{|c|c|c|c|c|c|c|}
\hline \multirow{2}{*}{$\begin{array}{l}\text { Taxon } \\
\text { order/family }\end{array}$} & \multirow{2}{*}{$\begin{array}{l}\text { Pollution. } \\
\text { tolerance }\end{array}$} & \multicolumn{4}{|c|}{$\begin{array}{c}\text { Number collected at } \\
\text { sampling site }\end{array}$} & \multirow{2}{*}{ Total } \\
\hline & & 1 & 2 & 3 & 4 & \\
\hline \multicolumn{7}{|l|}{ Ephemeroptera (mayflies) } \\
\hline Baetidae & 5 & 260 & 0 & 0 & 198 & 458 \\
\hline Caenidae & 6 & 5 & 0 & 0 & 0 & 5 \\
\hline Heptagenidae & 3 & 1 & 0 & 0 & 0 & 1 \\
\hline \multicolumn{7}{|l|}{ Trichoptera (caddis flies) } \\
\hline Hydropsychidae & 4 & 6 & 0 & 0 & 0 & 6 \\
\hline \multicolumn{7}{|c|}{ Odonata (damselflies and dragonflies) } \\
\hline Aeshnidae & 3 & 83 & 0 & 0 & 40 & 123 \\
\hline Coenagrionidae & 9 & 9 & 48 & 26 & 17 & 100 \\
\hline Libelulidae & 9 & 13 & 29 & 10 & 22 & 74 \\
\hline \multicolumn{7}{|c|}{ Hemiptera (water or true bugs) } \\
\hline Belostomatidae & 9 & 26 & 59 & 156 & 64 & 305 \\
\hline Corixidae & 8 & 34 & 87 & 14 & 82 & 217 \\
\hline Geridae & 6 & 1 & 0 & 3 & 5 & 9 \\
\hline Naucoridae & 8 & 0 & 0 & 0 & 24 & 24 \\
\hline Nepiedae & 7 & 10 & 0 & 16 & 0 & 26 \\
\hline Notonectidae & 9 & 25 & 16 & 18 & 14 & 73 \\
\hline Pleidae & 8 & 6 & 17 & 10 & 16 & 49 \\
\hline Veliidae & 7 & 9 & 13 & 2 & 26 & 50 \\
\hline \multicolumn{7}{|l|}{ Coleoptera (beetles) } \\
\hline Dytiscidae & 5 & 92 & 127 & 87 & 13 & 319 \\
\hline Elmidae & 4 & 45 & 9 & 17 & 25 & 96 \\
\hline Haliplidae & 5 & 55 & 137 & 154 & 13 & 359 \\
\hline Hydrophilidae & 5 & 46 & 302 & 52 & 9 & 409 \\
\hline \multicolumn{7}{|c|}{ Diptera (two winged / true flies) } \\
\hline Ceratopogonidae & 6 & 3 & 0 & 18 & 3 & 24 \\
\hline Chironomidae & 8 & 82 & 2338 & 714 & 386 & 3520 \\
\hline Culicidae & 8 & 12 & 725 & 96 & 27 & 860 \\
\hline Ephydridae & 6 & 0 & 1028 & 406 & 150 & 1584 \\
\hline Syrphidae & 10 & 0 & 140 & 0 & 0 & 140 \\
\hline \multicolumn{7}{|l|}{ Mollusks (snails) } \\
\hline Planorbidae & 7 & 4 & 9 & 12 & 36 & 61 \\
\hline Physidae & 8 & 15 & 0 & 27 & 17 & 59 \\
\hline \multicolumn{7}{|l|}{ Arachnida } \\
\hline Hydracarina (water mites) & 6 & 62 & 19 & 1 & 7 & 89 \\
\hline Hirudinae (Leeches) & 10 & 84 & 26 & 0 & 12 & 122 \\
\hline Total Individual & & 988 & 5129 & 1839 & 1206 & 9162 \\
\hline Total taxon & & 25 & 18 & 20 & 23 & 28 \\
\hline
\end{tabular}


Table 2. Effect of the tannery effluent on macroinvertebrate metrics at different Sites along Blue Nile River in 2010/11.

\begin{tabular}{|c|c|c|c|c|c|}
\hline Parameter & \%Taxa richness & \% EPT & \% Diptera & \% Dominant taxa & \% Non-insect taxa \\
\hline \multicolumn{6}{|l|}{ Sampling sites } \\
\hline$S_{1}$ & $78.0^{\mathrm{a}}$ & $32.9^{\mathrm{a}}$ & $9.7^{\mathrm{c}}$ & $37.0^{\mathrm{a}}$ & $14.9^{\mathrm{a}}$ \\
\hline $\mathrm{S}_{2}$ & $87.5^{\mathrm{a}}$ & $0.0^{\mathrm{b}}$ & $81.8^{\mathrm{a}}$ & $42.5^{\mathrm{a}}$ & $1.0^{\mathrm{b}}$ \\
\hline$S_{3}$ & $75.0^{\mathrm{a}}$ & $0.0^{\mathrm{b}}$ & $68.4^{\mathrm{a}}$ & $40.5^{\mathrm{a}}$ & $2.2^{\mathrm{b}}$ \\
\hline $\mathrm{S}_{4}$ & $78.0^{\mathrm{a}}$ & $18.2^{\mathrm{ab}}$ & $46^{\mathrm{b}}$ & $34.6^{\mathrm{a}}$ & $6.0^{\mathrm{ab}}$ \\
\hline Samplina sites & \multicolumn{5}{|c|}{ Macro-invertebrate metrics } \\
\hline Sampling sites & $\%$ Chironomi & dae & HFBI & SDI & BMI \\
\hline $\mathbf{S}_{1}$ & $8.0^{\mathrm{b}}$ & & $6.0^{\mathrm{b}}$ & $2.2^{\mathrm{a}}$ & $33^{a}$ \\
\hline $\mathrm{S}_{2}$ & $42.5^{\mathrm{a}}$ & & $7.3^{\mathrm{a}}$ & $1.7^{\mathrm{C}}$ & $18^{\mathrm{b}}$ \\
\hline $\mathrm{S}_{3}$ & $40.5^{\mathrm{a}}$ & & $7.1^{\mathrm{a}}$ & $1.8^{\mathrm{bc}}$ & $19^{b}$ \\
\hline $\mathrm{S}_{4}$ & $31.9^{\mathrm{a}}$ & & $6.9^{\mathrm{a}}$ & $2.0^{\mathrm{ab}}$ & $23^{\mathrm{b}}$ \\
\hline
\end{tabular}

Means within a column followed by the same letter are not significantly different from each other according toTukey HSD $(p<0.05)$.

Table 3. Categorization of sites in to different impairment levels based on BMI results

\begin{tabular}{lllc}
\hline BMI Value & Water quality characterization & Impairment & Sites at each impairment level \\
\hline $20-46$ & Very poor to poor & Severe to slight & $\mathrm{S}_{2}$ and $\mathrm{S}_{3}$ \\
$46-72$ & Fair to good & Moderate to less & $\mathrm{S}_{4}$ \\
$72-100$ & Very good to excellent & Very little to none & $\mathrm{S}_{1}$ \\
\hline
\end{tabular}

condensed into eight metrics represented different ecological characteristics along the river gradient. The results indicated that the reference site $\left(S_{1}\right)$ was different from the downstream sites, with slightly better biological activity at the reference site. Metric scores for each study site (Table 2) showed that the metrics closely follow pollution stress gradient. Percent Dipterans, \% DT, and $\mathrm{HFBI}$ increased with increase in perturbation while \% EPT and SDI showed a decreasing trend.

\section{Percent taxa richness}

The mean value of this metric ranged from $75 \%\left(\mathrm{~S}_{3}\right)$ to $87.5 \%\left(\mathrm{~S}_{2}\right)$. Taxa richness normally decreases with decreasing water quality (Vinson, 2006). Unlike the findings of Yandora (1998) and Birnesh (2007) and what is stated above, in this study, there was no significant difference in percent taxa richness among sampling sites $(\mathrm{F}=2.03, \mathrm{P}=0.18, \mathrm{R} 2=0.74$ ) (Table 2) and the upstream site showed lower diversity than the first downstream site. This might be due to the elimination of the sensitive taxa at the impacted sites.

Plafkin et al. (1989) stated that sites with greater than 26 taxa as non-impacted, 19-26 as slightly impacted, 1118 as moderately impacted and $0-10$ as severely impacted. Based on this criterion, the upstream site falls in slightly impacted range while the site just below the effluent falls in the moderately impacted range. So the low taxa richness at downstream sites is attributed to the low water quality and the strong negative response of percent taxa richness.

\section{Percent EPT}

The metrics has a zero value at severely impacted sites $\left(S_{2}\right.$ and $\left.S_{3}\right)$ and its value ranged from $0\left(S_{2}\right.$ and $\left.S_{3}\right)$ to $32.9\left(\mathrm{~S}_{1}\right)$. There was significant difference among sampling sites $\left(F=5.82, P=0.017, R^{2}=0.73\right)$; downstream sites having significantly lower value than the reference (upstream) site. Here, the last downstream site also had significantly higher value than the two downstream sites (Table 2), but there was no difference between $S_{1}$ and $S_{4}$ and also between $S_{2}$ and $S_{3}$.

Organisms in the EPT orders are qualified as indicators of good water quality. The higher the EPT index, the cleaner the stream (Perry, 2005). So their complete absence $S_{2}$ and $S_{3}$ and presence at the upstream site showed how seriously pollution affected these organisms. Yandora (1998), Baye (2006) and Birnesh (2007) reported the same result in absence of EPT at impacted sites. 


\section{Percent Diptera, Dominant Taxa and Chironomidae}

The value of percent Dipterans ranged from $9.7\left(S_{1}\right)$ to $81.77\left(\mathrm{~S}_{2}\right)$. Its values showed significant variation among sampling sites $\left(F=94.36, \quad P<0.0001, \quad R^{2}=0.97\right)$; the upstream site having significantly lower value than the downstream sites. But the last downstream site $\left(\mathrm{S}_{4}\right)$ also had significantly lower percent diptera than the rest downstream sites while $\mathrm{S}_{2}$ and $\mathrm{S}_{3}$ did not vary significantly (Table 2 ). This indicated the organic pollution load at downstream sites.

Percent chironomidae values ranged from $8.02\left(S_{1}\right)$ to $42.48\left(\mathrm{~S}_{2}\right)$. This index significantly vary among sampling sites $\left(F=23.93, P=0.0001, R^{2}=0.89\right)$; upstream site having significantly lower value than downstream sites. But the three downstream sites did not vary significantly (Table 2). The large abundance of chironomidae at downstream sites is an indication of organic pollution and nutrient enrichment. Yandora (1998) reported that a sample in which greater than $50 \%$ is chironomidae suggested eutrophic condition and chironomidae increase with a decrease in water quality. Weigel et al. (2002) also reported that chironomids were the only taxa at sites with severe point-source pollution.

Percent Chironomidae and percent Dominant Taxa showed similar trend. The two metrics had almost similar value at the downstream sites showing chironomids were the dominant taxa at downstream sites. But percent dominant taxa did not show significant variation among sampling sites (Table 2). Percent dominant taxon at $S_{2}$ and $S_{3}$ was higher than $S_{1}$ and it is the contribution of chironomidae. Its average values at these sites were 42.5 and $40.5 \%$, respectively. Percent dominant taxa greater than 45 indicate impaired, $40-45$ possible impaired and less than 40 unimpaired (Barbour et al., 1999) condition. In this study, $S_{2}$ and $S_{3}$ indicated possible impaired condition while $S_{1}$ (8.02) and $S_{4}$ (31.9) indicated unimpaired condition.

\section{Hilsenhoff family-level biotic index}

The value of this metrics ranged from $6\left(S_{1}\right)$ to $7.3\left(S_{2}\right)$. There was significant difference in its value among sampling sites $\left(F=15.48, \quad P=0.0007, R^{2}=0.85\right)$. The reference site scored a significantly lower value than the three downstream sites while the downstream sites did not show significant variation among them (Table 2). High values are indicative of organic pollution while low values are indicative of clean water (Hilsenhoff, 1988). In this study, the higher values at $S_{2}$ and $S_{3}$ are indicators of the organic pollution load from the tannery effluent.

\section{Shannon diversity index}

The value of this metrics followed a decreasing trend from reference site to the severely impacted sites indicating that it has been affected by pollutants and it was able to discriminate mild and severe impacts from reference condition. Its value ranged from $1.7\left(\mathrm{~S}_{2}\right)$ to 2.2 $\left(\mathrm{S}_{1}\right)$ and it significantly vary among sampling sites $\left(F=11.37, P=0.002, R^{2}=0.81\right)$. The reference site had significantly higher diversity than the two consecutive adjacent downstream sites $\left(S_{2}\right.$ and $S_{3)}$. Site four also had significantly higher value than $S_{2}$. But $S D I$ value of the upstream site did not show significant difference with the last downstream site and also $S_{2}$ with $S_{3}$ and $S_{3}$ with $S_{4}$ did not show significant variation (Table 2). The results of Baye (2006), and Birnesh (2007) also showed the decreasing trend of this index along pollution gradient.

\section{Benthic Macroinvertebrate Index (BMI)}

The BMI developed from the selected metrics ranged from $45\left(S_{2}\right)$ to $81\left(S_{1}\right)$ (Table 2). Its value showed significant difference among sites; the reference site $\left(S_{1}\right)$ having higher value than the three downstream sites. But the downstream sites did not show significant variation among them (Table 2).

\section{Categorization of Sites Based on BMI Values}

Even though, the above macro-invertebrate metrics categorize the sites into different impairment levels, the BMI calculated from the condensation of the metrics categorize the four sites into three actual impairment levels with their water quality status. Based on this, $S_{2}$ and $S_{3}$ were categorized into water quality status of very poor to Poor and impairment level of sever to slight. The other downstream site $\left(\mathrm{S}_{4}\right)$ was categorized in the fair to good water quality and moderate to less impairment level. But the upstream (reference) site was under very good to excellent water quality and very little to nonimpairment level (Table 3). The values of this metric followed pollution gradient, decreased with increase in pollution. The categorization of sites based on BMI values showed that the tannery effluent is seriously affecting the downstream sites (Figure 2).

\section{Conclusion}

The discharge of the highly concentrated pollutants into the river caused severe damage on the ecosystem. The impairment level at the two immediate downstream sites was severe while it was little to none at the reference site. Similarly, the water quality at the two immediate downstream sites was poor and the reference had excellent water quality. This high impairment of the downstream sites made the water unfavorable for domestic, agricultural and aesthetic use as pollutants like 

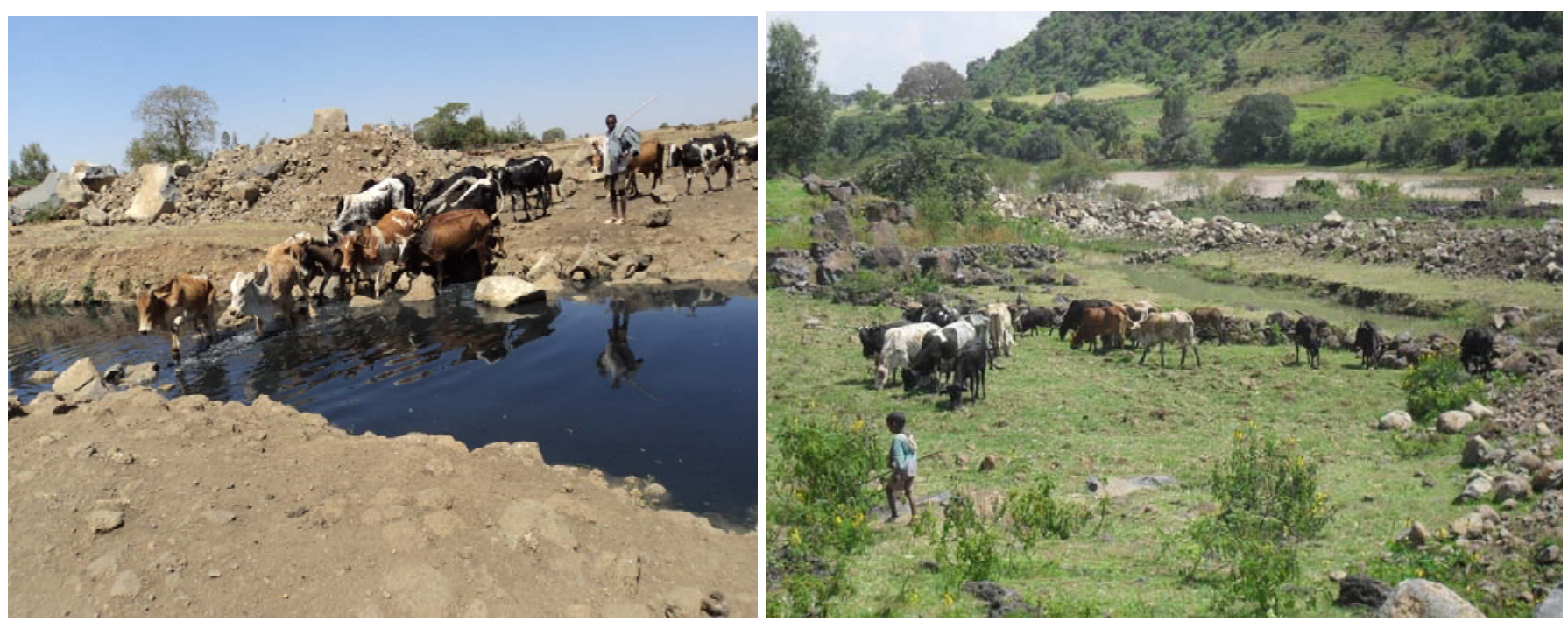

Cattles crossing the effluent stream

Cattles grazing around the effluent stream
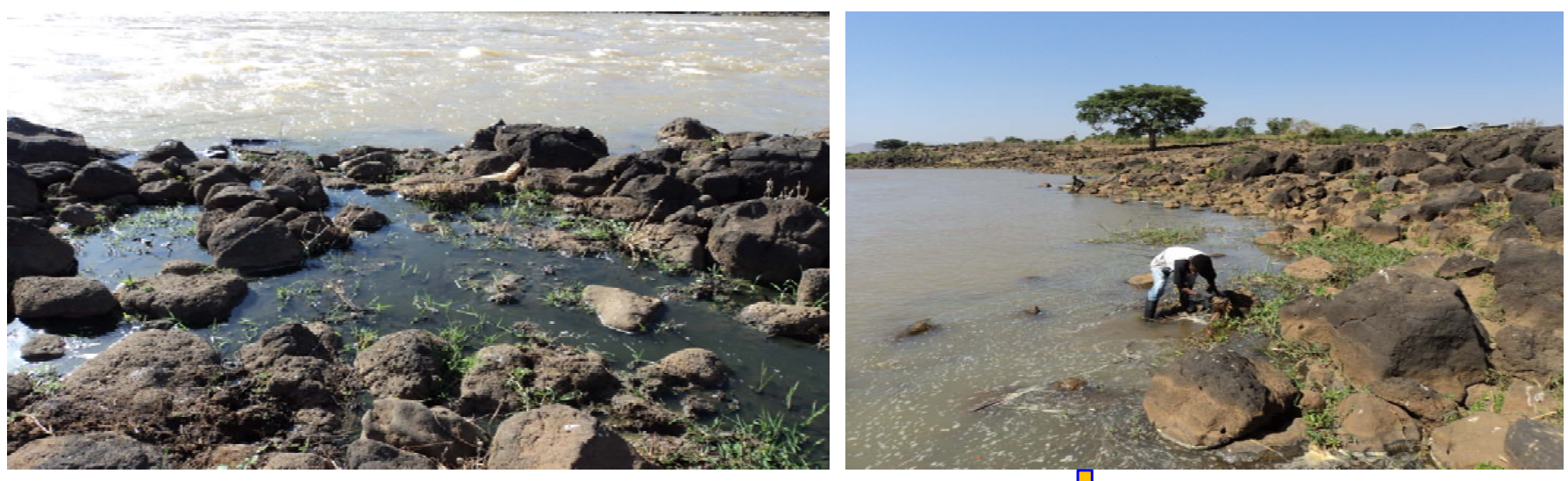

Effluent joining the river

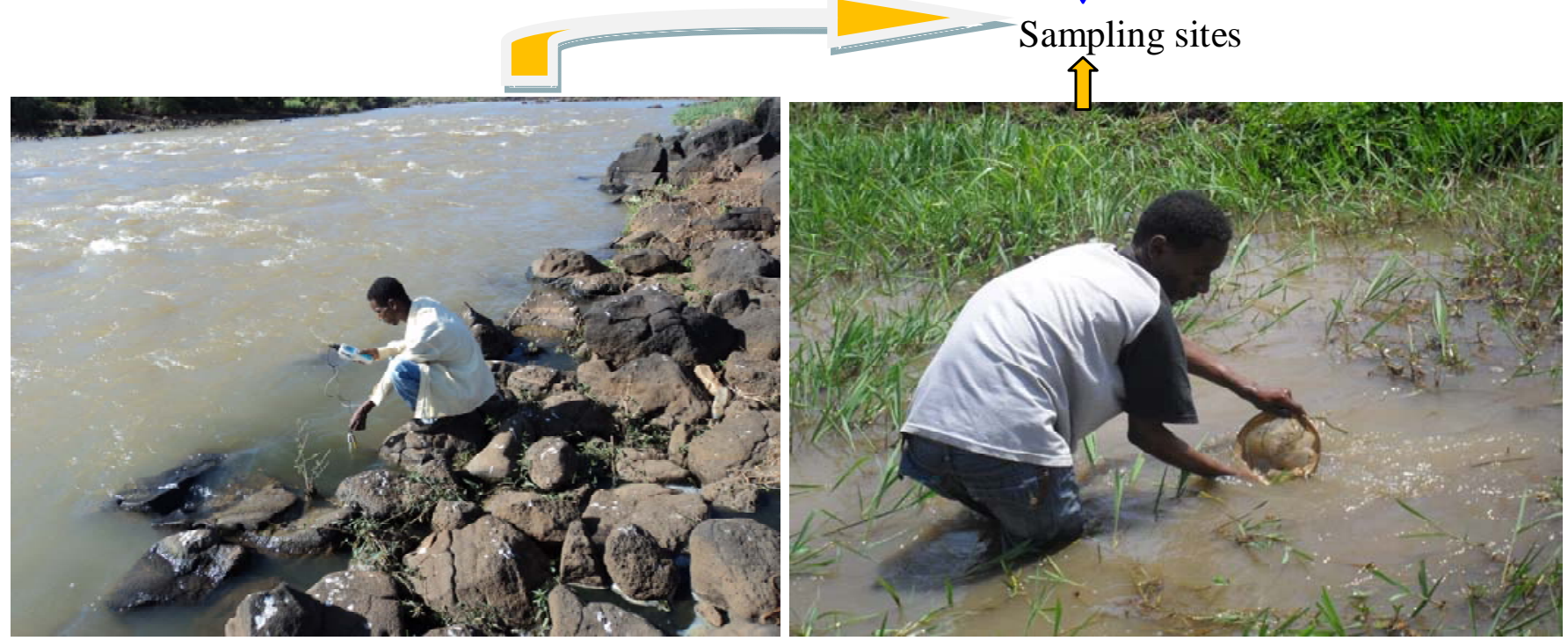

Figure 2. Plates showing some of the study sites and disturbances by the tannery effluent. 
chromium from the tannery had a bio-accumulating effect. The state of the downstream sites must regularly be brought to public awareness by arranging continuous meeting with the community and telling the information for them. The development of tanning industries in Ethiopia is an encouraging phenomenon due to the country's large livestock population and government's development policy since it improves the economy and standards of living of citizens. However, the associated pollution which results from the discharge of wastewater into the environment without considering its due ecological consequences could overweigh the benefits. This can be threatening and lead towards a devastating environmental condition, unless industrial wastes are managed properly. So, environmental protection laws which consider technical and financial capability of the industries must be established so as to control industrial pollution. Not only establishment, the laws should also be enforced and environmental standards with their protocols should be followed with strict and continuous monitoring.

\section{Conflict of Interests}

The author(s) have not declared any conflict of interests.

\section{ACKNOWLEDGEMENT}

The authors thank Amhara National Regional State for financial support and Bahir Dar University for the provision of material and laboratory facilities.

\section{REFERENCES}

Abel PD (1996). Water Pollution Biology. $2^{\text {nd }}$ Edn. London:Taylor and Francis

Barbour MT, Gerristen J, Snyder BD, Stribling JB (1999). Rapid bioassessment protoclos for use in streams and wadeable rivers: periphyton, benthic macroinvertebrates and fish, $2^{\text {nd }}$ Ed. EPA 841-B99-002. U.S. Environmental Protection Agency; Office of Water, Washington, D.C.

Barnard PC, Biggs J (1988). Macroinvertebrates in the catchment streams of Lake Naivasha, Kenya. Revue d'Hydrobiologie Tropicale 21:127-13.

Baye S (2006). Assessment of benthic-macroinvertebrate structures in relation to environmental degradation in some Ethiopian rivers, M.Sc Thesis, School of Graduate Studies, Addis Ababa University.

Birnesh A (2007). Assessment of downstream pollution profiles of Awassa textile factory effluent along Tikur Wuha river using physicochemical and macroinvertebrate indicators. M.Sc. Thesis. School of Graduate Studies, Addis Ababa University.

Bouchard RW (2004). Guide to aquatic macroinvertebrates of the upper midwest. Water resources center, University of Minnesota, St. Paul, MN.

Dallas HF (1997). A preliminary evaluation of aspects of SASS (South Africa Scoring System) for rapid bioassessment of water quality in rivers. South Afr. J. Aquat. Sci. 23: 79-94.

Edmondson WT (1959). Fresh water biology. $2^{\text {nd }}$ Edn. New York: John Wiley and Sons.

Farenzena M, Ferreira L, Trierweiler JO, Aquim PM (2005). Tanneries: from waste to sustainability. Braz. Arch. Boil. Technol. 48 (Special n): 281-289.

Favazzi A (2002). 'Study of the impact of the main policies and environment protection measures in Africa's leather industry', Paper presentation and study for Meet in Africa. 2002, Retrieved on 10 May 2010,

http://www.unido.org/fileadmin/import/10203_StudioFavazzi.4.pdf

Gooderham J, Tysrlin E (2002). The water bug book: A guide to the freshwater macroinvertebrates of temperate Australia. Australia: Csiro publishing.

Hayal D, Seyoum M (2009). Water quality parameters and macroinvertebrates index of biotic integrity of the Jimma wetlands, Southwestern Ethiopia. J. Wetlands Ecol. 3: 77-93.

Hilsenhoff W L (1988). Rapid field assessment of organic pollution with a family level biotic index. J. N. Am. Benthol. Soc. 7(1): 65-68.

Jessup BK, Markowitz A, Stribling JB (1999). Family-level key to the stream invertebrates of Maryland and surrounding areas. Maryland department of natural resources Chesapeake Bay and watershed program resource assessment service monitoring and non-tidal assessment division CBWP-MANTA-EA-99-2.

Karr JR (1981). Assessment of biotic integrity using fish communities. Fisheries 6(6):21-27.

Khan SR, Khwaja MA, Khan AM, Ghani H, Kazmi S (1999). Environmental impacts and mitigation costs associated with cloth and leather exports from Pakistan. A report on trade and sustainable development submitted by sustainable development policy institute and IUCN-P to IISD Canada for the IISD/IUCN/IDRC project on building capacity for trade and sustainable development in developing countries, Islamabad.

Kinyua AM, Pacini N (1991). The impact of pollution on the ecology of the Nairobi-Athi river system in Kenya. Int. J. Biochem. Biophysiol. 1:5- 7 .

Klemm DJ, Lewis PA, Fulk F, Lazorchak JM (1990). Macroinvertebrate field and laboratory methods for evaluating the biological integrity of surface waters. EPA/600/4-90/030. U.S. Environmental protection agency: Office of research and development, Washngton D.C.

Mason CF (1990). Biological Aspects of Freshwater.Pollution. In: Harrison, R.M. (ed) Pollutions: causes, effect and control. Royal Society of Chemistry, London. pp. $99-125$.

Mathooko JM (2002). The sizes, maturity stages and biomass of mayfly assemblages colonizing disturbed streambed patches in central Kenya. Afr. J. Ecol. 40:84 93.

Mondal NC, Saxena VK, Singh VS (2005). Impact of pollution due to tanneries on groundwater regime. Curr. Sci. 88(12):25.

Ogedengbe K, Akinbile CO (2004). Impact of industrial pollutants on quality of ground and surface waters at Oluyole Industrial Estate, Ibadan, Nigeria. J. Technol. Dev. 4(2):139-144.

Perry JB (2005). Biotic indices of stream macroinvertebrates for fun and (educational) profit. In: Tested Studies for Laboratory Teaching, Volume 26 (M.A. O'Donnell, Editor). Proceedings of the 26th Workshop/Conference of the Association for Biology Laboratory Education (ABLE). pp. 281-294.

Plafkin JL, Barbour MT, Porter KD, Gross SK, Hughes RM (1989). Rapid bioassessment protocols for use in streams and rivers. Benthic macroinvertebrates and fish. EPA 440-4-89-00. U.S. Environmental protection agency; Office of water regulations and standards, Washington, D.C.

Solomon A (2006). Assessing the biological integrity of the great Akaki River using macroinvertebrates. M.Sc Thesis, School of Graduate Studies, Addis Ababa University.

Suflita JM, Robinson JM, Tiedje JM (1983). Kinetics of microbial dehalogenation of haloaromatic substrates in methanogenic environment. Appl. Environ. Microbiol. 45(5):1466-1473.

Tumiwesigye C, Yusuf SK, Makanga B (2000). Structure and composition of benthic macroinvertebrate of a tropical forest stream, River Nyamweru, western Uganda. Afr. J. Ecol. 38:72-77.

Verheijen LA, Wiersema D, Hulshoff LW, De Wit J (1996). Livestock and the environment finding a balance: Management of waste from animal product processing. International agriculture centre Wageningen, The Netherlands.

Vinson M (2006). Aquatic Invertebrate Report for samples collected from the Six Rivers National Forest. Report prepared for: United 
States Forest Service Six Rivers National Forest Lower Trinity Road 1330 Bayshore Way,Eureka, California 95501.

Weigel BM, Henne LJ, Martínez-Rivera LM (2002). Macroinvertebratebased index of biotic integrity for protection of streams in WestCentral Mexico. J. N. Am. Benthol. Soc. 21(4):686-700.

Yandora K (1998). Rapid bioassessment of benthic macroinvertebrates illustrates water quality in small order urban streams in a North Carolina Piedmont City. City of Greensboro, storm water services, 401 Patton Avenue, Greensboro, North Carolina 27406.
Zinabu G-M, Zerihun D (2002). The chemical compostion of the effluent from Awassa Textile factory and its effects on aquatic biota. SINET: Ethiopian Journal of Science 25(2):263-274. 